\title{
Expression and prognostic value of matriptase in ovarian serous adenocarcinoma
}

\author{
MEI JI*, SHUNSHUANG LI*, YA XIE, ZHAO ZHAO, WEIZHONG CHANG, YUE LI, \\ XINGHAN CHENG and ZHUO WANG
}

\begin{abstract}
Department of Obstetrics and Gynecology, The First Affiliated Hospital of Zhengzhou University, Zhengzhou, Henan 450052, P.R. China
\end{abstract}

Received February 5, 2015; Accepted March 1, 2016

DOI: $10.3892 / 01.2017 .5600$

\begin{abstract}
Previous studies have demonstrated that matriptase is involved in degradation of the extracellular matrix and angiogenesis, and is overexpressed in certain forms of epithelial cancer. The present study aimed to examine matriptase expression in ovarian serous adenocarcinoma, and to investigate its association with clinicopathological characteristics and patient prognosis. Matriptase expression was analyzed in 80 ovarian serous adenocarcinoma and 12 normal ovarian tissue samples by immunohistochemistry. All data were analyzed to evaluate the association between matriptase expression and clinicopathological parameters and overall survival. Immunohistochemistry demonstrated that matriptase protein was significantly overexpressed in the ovarian serous adenocarcinoma tissues compared with the normal ovarian tissues $(\mathrm{P}=0.0003)$. Furthermore, matriptase expression was significantly associated with clinical stage $(\mathrm{P}=0.0077)$ and lymph node metastasis $(\mathrm{P}=0.0111)$. Kaplan-Meier survival curves demonstrated that patients with positive matriptase expression had significantly greater survival times $(\mathrm{P}=0.0008)$. Matriptase expression is associated with early stage and a greater survival time; therefore, this protein may function as a novel diagnostic and prognostic marker.
\end{abstract}

\section{Introduction}

Ovarian cancer is the leading cause of gynecological malignancy-associated mortality. Patients diagnosed during the early stages of the disease (stage I-II) have a more favorable prognosis compared with patients who are diagnosed

Correspondence to: Mrs. Shunshuang Li, Department of Obstetrics and Gynecology, The First Affiliated Hospital of Zhengzhou University, 1 Jianshe East Road, Zhengzhou, Henan 450052, P.R. China

E-mail: lishunshuang@163.com

${ }^{*}$ Contributed equally

Abbreviations: FIGO, International Federation of Gynecology and Obstetrics; PBS, phosphate-buffered saline

Key words: matriptase, ovarian serous adenocarcinoma, prognosis, immunohistochemistry during later stages (stage III-IV) (1,2). Advanced-stage disease, dissemination, metastasis and resistance to chemotherapeutic drugs all contribute to the high mortality rate $(\sim 60 \%)$ associated with ovarian cancer $(1,2)$. Novel therapies with higher success rates are urgently required, in addition to the identification of potential therapeutic targets and prognostic markers.

Matriptase is a type II transmembrane serine protease that facilitates cellular invasiveness, and is also considered to activate oncogenic pathways (3). The enzyme was first identified in human breast carcinoma (3). Matriptase is expressed in epithelial cells (4) and has been detected in a large proportion of human epithelium-derived tumor tissues, including ovarian carcinoma (5), prostate cancer (6), breast cancer (3), colorectal carcinoma (7), stomach cancer (8), renal cancer (9), cervical cell carcinoma (10) and endometrial cancer (11). The protein has also been reported to promote malignant progression in a number of animal models (12). Matriptase is considered to have pleiotropic functions, including modulation of tumor cell-substratum adhesion, degradation of the extracellular matrix, tissue remodeling, tumor growth and metastasis (3). In the current study, the expression of matriptase was examined using immunohistochemical techniques, and the association between matriptase expression and clinicopathological characteristics and prognosis in patients with ovarian serous adenocarcinoma was investigated.

\section{Materials and methods}

Patients. Ovarian serous adenocarcinoma specimens were obtained from 80 patients during surgery at the Department of Obstetrics and Gynecology of The First Affiliated Hospital of Zhengzhou University (Zhengzhou, China) between February 2006 and March 2011. Optimal surgery was attempted in all patients. Laparoscopic comprehensive staging surgery was performed in early stage patients, while reduction surgery was performed in later stage patients, according to the National Comprehensive Cancer Network guidelines (13). Patients were not subjected to radiotherapy or chemotherapy prior to surgery. Stage $\mathrm{Ia} / \mathrm{Ib}$ and grade 1 patients received no further treatment, whilst stage Ic, II, III or IV and grade $2 / 3$ patients were treated with platinum-based chemotherapy $\left(80 \mathrm{~kg} / \mathrm{m}^{2}\right.$ intravenous nedaplatin, 6-8 cyles). The age of the patients ranged from 28 to 83 years (mean, 55.78 years). All specimens were used in the 
Table I. Association between matriptase and clinicopathological parameters in ovarian serous adenocarcinoma.

\begin{tabular}{|c|c|c|c|}
\hline Variable & $\begin{array}{c}\text { Total } \\
\text { patients, } \mathrm{n}\end{array}$ & $\begin{array}{c}\text { Positive matriptase } \\
\text { expression, } \mathrm{n}(\%)\end{array}$ & P-value \\
\hline Age, years & & & 0.2240 \\
\hline$<50$ & 38 & $22(57.8)$ & \\
\hline$\geq 50$ & 42 & $23(54.8)$ & \\
\hline Clinical stage & & & $0.0077^{\mathrm{a}}$ \\
\hline $\mathrm{I} / \mathrm{II}$ & 29 & $22(75.9)$ & \\
\hline III/IV & 51 & $23(45.1)$ & \\
\hline Histological grade & & & 0.2595 \\
\hline 1 & 49 & $30(61.2)$ & \\
\hline $2 / 3$ & 31 & $15(48.4)$ & \\
\hline Lymph node metastasis & & & $0.0111^{\mathrm{a}}$ \\
\hline No & 38 & $27(71.1)$ & \\
\hline N1 & 42 & $18(42.9)$ & \\
\hline Residual tumor post-surgery & & & 0.7636 \\
\hline$\leq 1 \mathrm{~cm}$ & 54 & $31(57.4)$ & \\
\hline$>1 \mathrm{~cm}$ & 26 & $14(53.8)$ & \\
\hline Ascites & & & 0.7968 \\
\hline Yes & 33 & $18(54.5)$ & \\
\hline No & 47 & $27(57.4)$ & \\
\hline
\end{tabular}

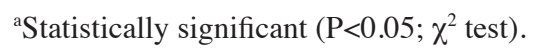

present study after obtaining written informed consent from the patients, and ethical approval was provided by the Ethics Review Board of Life Sciences, Zhengzhou University. According to the 2010 International Federation of Gynecology and Obstetrics (FIGO) grading system (14), tumor histological grade was classified as poorly-differentiated (grade 3; 11/80 patients), moderately-differentiated (grade $2 ; 20 / 80$ patients) or well-differentiated (grade 1; 49/80 patients). Surgical staging was reviewed based on the FIGO staging system as follows: 9 patients were allocated to stage I, 20 patients to stage II, 33 patients to stage III and 18 patients to stage IV. In the follow-up care clinic, patients were evaluated every month in the first 6 months, every 2 months in the subsequent 6 months, and every 3 months in the second year. Subsequently, follow-up care was conducted annually.

In total, 12 normal ovarian tissue specimens were obtained from patients undergoing hysterectomies for non-ovarian disease: 7 patients underwent oophorectomy for uterine myoma and 5 patients underwent surgery for adenomyosis. The age of the patients ranged from 53 to 83 years (mean, 69.58 years). Written informed consent was obtained from these patients.

Immunohistochemistry. Paraffin-embedded tissues were obtained from the archive of the Department of Pathology, of The First Affiliated Hospital of Zhengzhou University, and were cut to a thickness of $4 \mu \mathrm{m}$. The tissue sections were baked at $60^{\circ} \mathrm{C}$, dewaxed in xylene and rehydrated in a graded alcohol series following 3 washes (each for $3 \mathrm{~min}$ ) in phosphate-buffered saline (PBS). Antigen retrieval was performed by heating each section to $100^{\circ} \mathrm{C}$ for $20 \mathrm{~min}$ in $0.01 \mathrm{~mol} / 1$ sodium citrate buffer
Table II. Univariate analysis of overall survival in patients with ovarian serous adenocarcinoma.

\begin{tabular}{lr}
\hline Factor & P-value \\
\hline Age (<50 vs. $\geq 50$ years) & 0.5572 \\
Matriptase expression (positive vs. negative) & $0.0008^{\mathrm{a}}$ \\
Clinical stage (I/II vs. III/IV) & $<0.0001^{\mathrm{a}}$ \\
Histological grade (1 vs. 2/3) & $<0.0001^{\mathrm{a}}$ \\
Lymph node metastasis (N0 vs. N1) & $<0.0001^{\mathrm{a}}$ \\
Residual tumor post-surgery ( $\leq 1 \mathrm{vs.}>1 \mathrm{~cm})$ & $<0.0001^{\mathrm{a}}$ \\
Ascites (yes vs. no) & 0.5354
\end{tabular}

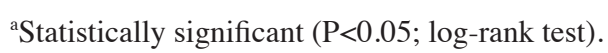

(pH 6.0). Sections were subsequently immersed in $3 \%$ hydrogen peroxide for $10 \mathrm{~min}$ to suppress endogenous peroxidase activity. Following 3 additional washes with PBS, sections were immersed in goat serum (Gibco ${ }^{\circledR}$; Thermo Fisher Scientific, Inc., Waltham, MA, USA) for $10 \mathrm{~min}$ and incubated with a rabbit polyclonal anti-matriptase/suppression of tumorigenicity 14 (ST14) antibody (catalog no. ab106842; 1:100; Abcam, Cambridge, UK) diluted in PBS at $4^{\circ} \mathrm{C}$ overnight. The sections were washed again 3 times (each for $3 \mathrm{~min}$ ) in PBS, and incubated with horseradish peroxidase-labeled mouse anti-rabbit polyclonal immunoglobulin antibody (catalog no. E0433; dilution, 1:250; Dako, Glostrup, Denmark) for $20 \mathrm{~min}$ at room temperature. The sections underwent a further 3 washes (each for 3 min) in PBS 
Table III. Multivariate analysis of overall survival in patients with ovarian serous adenocarcinoma.

\begin{tabular}{lccc}
\hline Factor & RR & 95\% CI & P-value \\
\hline Age (<50 vs. $\geq 50$ years) & 1.149 & $0.647-2.040$ & 0.6359 \\
Matriptase expression (positive vs. negative) & 0.754 & $0.390-1.460$ & 0.6994 \\
Clinical stage (I/II vs. III/IV) & 16.962 & $7.383-38.966$ & $<0.0001^{\text {a }}$ \\
Histological grade (1 vs. 2/3) & 1.126 & $0.756-1.676$ & 0.5607 \\
Lymph node metastasis (N0 vs. N1) & 22.337 & $4.632-107.724$ & $0.0001^{\text {a }}$ \\
Residual tumor post-surgery ( $\leq 1$ vs. $>1 \mathrm{~cm})$ & 1.109 & $0.581-2.118$ & 0.7530 \\
Ascites (yes vs. no) & 1.125 & $0.651-1.944$ & 0.6735 \\
\hline
\end{tabular}

RR, risk ratio; CI, confidence interval. aStatistically significant $(\mathrm{P}<0.05$; Cox proportional hazards regression model).

and were developed in 3,3'-diaminobenzidine (Biosynthesis Biotechnology Co., Ltd., Beijing, China). Following washing with distilled water, the sections were placed into hematoxylin (ComWin Biotech Co., Ltd., Beijing, China) for 5 min. Lastly, the sections were dehydrated in a graded alcohol series, cleared in xylene and resealed in natural resin (ComWin Biotech Co., Ltd.). PBS was used as a negative control instead of ST14 antibody. Olympus IMT-2 Microscope (Olympus Corporation, Tokyo, Japan) was used to view the slides.

Statistical analysis. SPSS version 17.0 (SPSS, Inc., Chicago, IL, USA) was used to perform statistical analysis. The $\chi^{2}$ or Fisher's exact test was used to analyze the association between clinicopathological parameters and matriptase expression. Kaplan-Meier analysis was used to construct survival curves, and the impact of matriptase expression on survival was assessed using the log-rank test and Cox proportional hazards regression model. $\mathrm{P}<0.05$ was considered to indicate a statistically significant difference.

\section{Results}

Immunohistochemical analysis of matriptase. Positive matriptase staining was observed in the cytoplasm and cell surface of the ovarian carcinoma cells, while the normal ovarian cells exhibited negative staining (Fig. 1). Matriptase staining was observed in $45(56.3 \%)$ out of 80 ovarian serous adenocarcinoma tissues, while all the normal ovarian tissues demonstrated negative staining $(\mathrm{P}=0.0003)$. Positive matriptase expression was significantly associated with clinical stage $(\mathrm{P}=0.0077)$ and lymph node metastasis $(\mathrm{P}=0.0111)$, and matriptase was detected more frequently in early stage cases than in advanced stage cases [stage I-II, 22/29 (75.9\%); stage III-IV, 23/51 (45.1\%); $\mathrm{P}=0.0077]$. No significant association was observed between positive matriptase expression and patient age, histological grade, residual tumor post-surgery or ascites (Table I).

Survival analysis. For the univariate analysis, log-rank testing identified that advanced clinical stage $(\mathrm{P}<0.0001)$, high histological grade $(\mathrm{P}<0.0001)$, lymph node metastasis $(\mathrm{P}<0.0001)$, large residual tumor post-surgery $(\mathrm{P}<0.0001)$ and negative matriptase expression $(\mathrm{P}=0.0008)$ were significantly correlated with poor overall survival times (Table II). Patients with ovarian serous adenocarcinoma were categorized along a
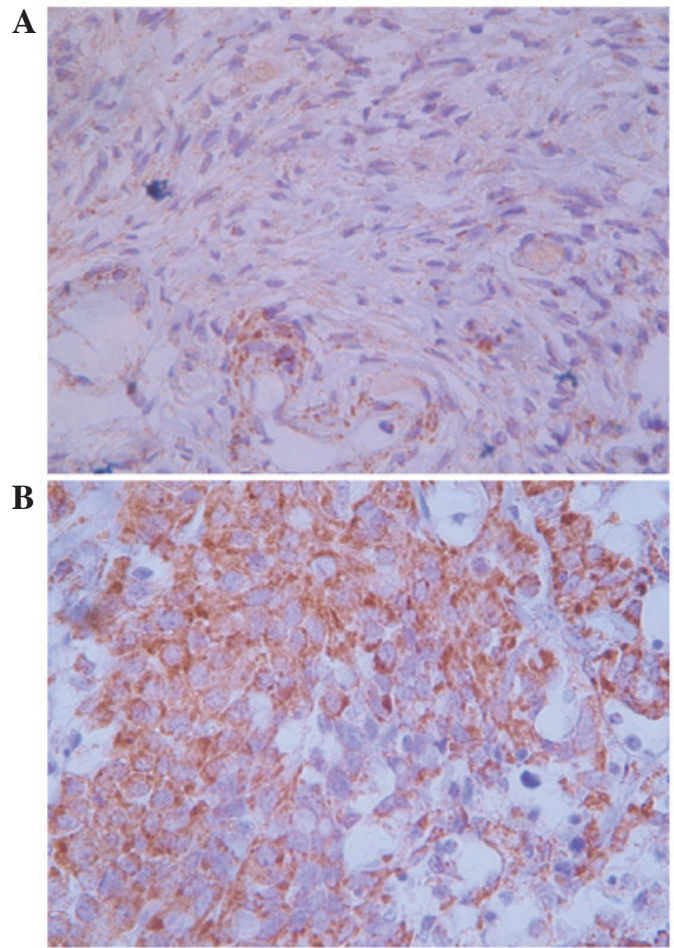

Figure 1. Characterization of matriptase expression in (A) human normal ovarian tissue and (B) ovarian carcinoma tissue by immunohistochemistry (magnification, x400). Representative images are presented.

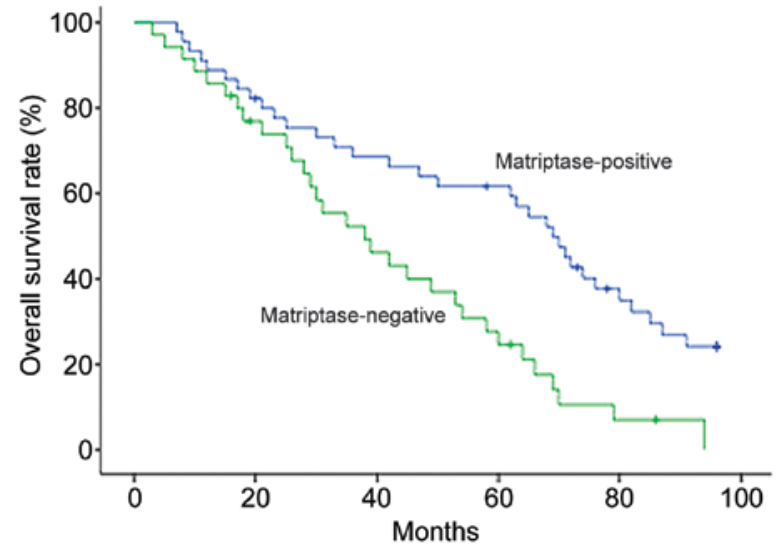

Figure 2. Kaplan-Meier plots representing overall survival of 80 patients with ovarian serous adenocarcinoma according to matriptase expression (negative vs. positive, $\mathrm{P}=0.0008$ ). 
Kaplan-Meier survival curve according to negative vs. positive matriptase expression and a statistically significant association was observed between negative matriptase expression and poor overall survival (Fig. $2 ; \mathrm{P}=0.0008$ ). For the multivariate analysis, clinical stage and lymph node metastasis were identified as significant and independent variables affecting survival $(\mathrm{P}<0.0001$ and $\mathrm{P}=0.0005$, respectively). None of the other variables were significantly associated with overall survival time in multivariate models (Table III).

\section{Discussion}

In the present study, a significantly higher rate of positive matriptase expression was detected by immunohistochemistry in ovarian serous adenocarcinoma tissues compared with normal ovarian tissue, thus indicating that matriptase may serve as a biomarker for ovarian cancer.

It is widely known that tumor cells utilize cell surface and extracellular proteolytic enzymes to degrade basement membrane proteins and achieve invasion $(15,16)$. Proteolytic enzymes participate in various cellular activities, including degradation of the extracellular matrix, migration, blood coagulation, adhesion, cell growth, apoptosis and differentiation (17). Pro-urokinase plasminogen activator and pro-hepatocyte growth factor are substrates for matriptase $(18,19)$, and all serve an important role in neoplastic progression, ranging from degradation of the extracellular matrix and basement membrane proteins to ovarian carcinoma cell proliferation (20).

Among the clinicopathological data examined in the present study, the expression of matriptase was significantly more frequent in patients with early stage ovarian cancer (stage I-II) compared with patients with advanced stages (stage III-IV), and in patients without lymph node metastasis compared with those with lymph node metastasis. These results indicate that matriptase expression primarily affects initial tumor development, and that the level of its expression is downregulated during cancer progression. Furthermore, it suggests that matriptase may be involved in the development of primary ovarian neoplasia and that, with cancer progression and invasion, its function becomes inhibitory. The exact role of matriptase in the progression and invasion of ovarian cancer remains unclear. A previous study reported that an imbalance in the ratio of matriptase to its inhibitor, hepatocyte growth factor activator inhibitor-1, may be important in the development of tumors (20). According to Kaplan-Meier plots from the present study, patients with positive matriptase expression have a longer survival time compared with patients with negative matriptase expression, however multivariate analyses have not demonstrated similar significant results. Matriptase may not be an independent prognostic factor for ovarian carcinoma; however, the protease is significantly associated with early stages of the disease and greater patient survival time.

In conclusion, the results of the present study indicate that a high level of matriptase expression is frequent in early stage ovarian cancer relative to that in normal ovarian tissues. This suggests that matriptase may participate in the formation of ovarian tumors, and may therefore serve as a marker for early diagnosis of this disease. Further study is required to confirm that this gene has clinical implications as an individualized treatment strategy for ovarian cancer.

\section{References}

1. Siegel R, Naishadham D and Jemal A: Cancer statistics, 2013. CA Cancer J Clin 63: 11-30, 2013.

2. Jemal A, Bray F, Center MM, Ferlay J, Ward E and Forman D: Global cancer statistics. CA Cancer J Clin 61: 69-90, 2011.

3. Uhland K: Matriptase and its putative role in cancer. Cell Mol Life Sci 63: 2968-2978, 2006.

4. Nakamura K, Hongo A, Kodama J, Abarzua F, Nasu Y, Kumon H and Hiramatsu Y: Expression of matriptase and clinical outcome of human endometrial cancer. Anticancer Res 29: 1685-1690, 2009.

5. Tanimoto H, Underwood LJ, Wang Y, Shigemasa K, Parmley TH and O'Brien TJ: Ovarian tumor cells express a transmembrane serine protease: A potential candidate for early diagnosis and therapeutic intervention. Tumour Biol 22: 104-114, 2001.

6. Saleem M, Adhami VM, Zhong W, Longley BJ, Lin CY, Dickson RB, Reagan-Shaw S, Jarrard DF and Mukhtar H: A novel biomarker for staging human prostate adenocarcinoma: Overexpression of matriptase with concomitant loss of its inhibitor, hepatocyte growth factor activator inhibitor-1. Cancer Epidemiol Biomarkers Prev 15: 217-227, 2006

7. Vogel LK, Saeb $\varnothing$ M, Skjelbred CF, Abell K, Pedersen ED, Vogel U and Kure EH: The ratio of Matriptase/HAI-1 mRNA is higher in colorectal cancer adenomas and carcinomas than corresponding tissue from control individuals. BMC Cancer 6: 176, 2006.

8. Zeng L, Cao J and Zhang X: Expression of serine protease SNC19/matriptase and its inhibitor hepatocyte growth factor activator inhibitor type 1 in normal and malignant tissues of gastrointestinal tract. World J Gastroenterol 11: 6202-6207, 2005.

9. Jin JS, Chen A, Hsieh DS, Yao CW, Cheng MF and Lin YF: Expression of serine protease matriptase in renal cell carcinoma: Correlation of tissue microarray immunohistochemical expression analysis results with clinicopathological parameters. Int J Surg Pathol 14: 65-72, 2006.

10. Santin AD, Cane' S, Bellone S, Bignotti E, Palmieri M, De Las Casas LE, Anfossi S, Roman JJ, O'Brien T and Pecorelli S: The novel serine protease tumor-associated differentially expressed gene-15 (matriptase/MT-SP1) is highly overexpressed in cervical carcinoma. Cancer 98: 1898-1904, 2003.

11. Nakamura K, Hongo A, Kodama J, Abarzua F, Nasu Y, Kumon H and Hiramatsu Y: Expression of matriptase and clinical outcome of human endometrial cancer. Anticancer Res 29: 1685-1690, 2009

12. List K, Bugge TH and Szabo R: Matriptase: Potent proteolysis on the cell surface. Mol Med 12: 1-7, 2006.

13. Bristow RE, Chang J, Ziogas A, Campos B, Chavez LR and Anton-Culver H: Impact of National Cancer Institute Comprehensive Cancer Centers on ovarian cancer treatment and survival. J Am Coll Surg 220: 940-950, 2015.

14. Zeppernick F and Meinhold-Heerlein L: The new FIGO staging system for ovarian, fallopian tube, and primary peritoneal cancer. Arch Gynecol Obstet 290: 839-842, 2014.

15. Chang $\mathrm{C}$ and Werb Z: The many faces of metalloproteases: Cell growth, invasion, angiogenesis and metastasis. Trends Cell Biol 11: S37-S43, 2001.

16. Del Rosso M, Fibbi G, Pucci M, D'Alessio S, Del Rosso A, Magnelli L and Chiarugi V: Multiple pathways of cell invasion are regulated by multiple families of serine proteases. Clin Exp Metastasis 19: 193-207, 2002.

17. Lisk K, Bugge TH and Szabo R: Matriptase: Potent proteolysis on the cell surface. Mol Med 12: 1-7, 2006.

18. Takeuchi T, Harris JL, Huang W, Yan KW, Coughlin SR and Craik CS: Cellular localization of membrane-type serine protease 1 and identification of protease-activated receptor- 2 and single-chain urokinase-type plasminogen activator as substrates. J Biol Chem 275: 26333-26342, 2000.

19. Lee SL, Dickson RB and Lin CY: Activation of hepatocyte growth factor and urokinase/plasminogen activator by matriptase, an epithelial membrane serine protease. J Biol Chem 275: 36720-36725, 2000.

20. Oberst MD, Johnson MD, Dickson RB, Lin CY, Singh B, Stewart M, Williams A, al-Nafussi A, Smyth JF, Gabra H and Sellar GC: Expression of the serine protease matriptase and its inhibitor HAI-1 in epithelial ovarian cancer: Correlation with clinical outcome and tumor clinicopathological parameters. Clin Cancer Res 8: 1101-1107, 2002. 